\title{
Effects of Vacuum Freeze-Drying and Vacuum Spray-Drying on Biochemical Properties and Functionalities of Myofibrillar Proteins from Silver Carp
}

\author{
Jianzhen Niu, ${ }^{1,2}$ Binfan Zhao, ${ }^{1,2}$ Xiujin Guo $\mathbb{D}^{1,3}$ and Tao Yin $\mathbb{D}^{2,4}$ \\ ${ }^{1}$ Key Laboratory of Refrigeration and Conditioning Aquatic Products Processing, Xiamen, Fujian Province 361026, China \\ ${ }^{2}$ College of Food Science and Technology, Huazhong Agricultural University, Wuhan, Hubei Province 430070, China \\ ${ }^{3}$ Fujian Anjoy Food Co., Ltd., Xiamen, Fujian 361026, China \\ ${ }^{4}$ National R \& D Branch Center for Conventional Freshwater Fish Processing, Wuhan, Hubei 430070, China \\ Correspondence should be addressed to Xiujin Guo; xiujin.hi@163.com and Tao Yin; yintao@mail.hzau.edu.cn
}

Received 10 April 2019; Accepted 3 July 2019; Published 4 August 2019

Academic Editor: Luis Patarata

Copyright (C) 2019 Jianzhen Niu et al. This is an open access article distributed under the Creative Commons Attribution License, which permits unrestricted use, distribution, and reproduction in any medium, provided the original work is properly cited.

Fish protein powders were produced from silver carp myofibrillar proteins using vacuum freeze-drying and vacuum spray-drying. Biochemical properties and functionalities of freeze-dried and spray-dried powders were determined. The myofibrillar proteins were partially denatured under both the drying methods which were evidenced by the increase of free sulfhydryl content, surface hydrophobicity, and intrinsic fluorescence while the decrease of the $\mathrm{Ca}^{2+}$-ATPase activity and percentage of the $\alpha$-helical structure. With respect to vacuum freeze-drying, the proteins were denatured to a higher degree by vacuum spray-drying. The spray-dried fish protein powder showed a higher water retention capacity and emulsifying stability index, but the same solubility and emulsifying activity index. The micrographs indicate that vacuum freeze-dried powder formed a spongy structure, while the powder under vacuum spray-drying mostly appeared spherical in shape with hollow inside. Thus, the two drying methods can be used to manufacture fish protein powders with varied molecular structures and functionalities.

\section{Introduction}

Fish is an important protein resource, which accounts for about 17 percent of animal protein consumed by the global population [1]. Fish proteins possess high digestibility, bioavailability, and several functional activities [2]. Silver carp (Hypophthalmichthys molitrix), one kind of freshwater fish, is widely farmed in China with an annual production of around 4 million ton [3]. It can steadily provide protein for human consumption, owing to its attributes of fast growing, low price, and sustainable availability. Currently, the majority of silver carp are used as the raw material for the production of frozen surimi (concentrated myofibrillar proteins) [4]. In the storage and distribution, freezing facilities with large space are needed to maintain the safety and functionality of surimi, which eventually push up costs for factories. Fish protein in the form of dehydrated powder owns numerous advantages in commerce, such as low distribution and storage costs, ease of packaging, light weight, and convenience of premixing with other powder ingredients.

Vacuum freeze-drying is a low-temperature dehydration process which involves freezing the food product, lowering air pressure, and then removing the water by sublimation [5]. In the recent years, vacuum freeze-drying technology has been used increasingly for protein foods including fish fillet [6], meat [7], krill [8], milk [9], surimi, and seafoods [10]. Functionality and nutrition of proteins are able to be well maintained, attributing to the low temperature throughout the drying process [5]. Reynolds et al. [11] studied the effect of vacuum freeze-drying on the quality of surimi, and found that the gel strain of the dried surimi showed a lower decline rate than the traditional frozen surimi during storage. Guo et al. [10] reported that fish 
myofibrillar proteins were mildly unfolded after vacuum freeze-drying, resulting in the enhancement of cross-linking reactions catalyzed by transglutaminase. Nevertheless, information on properties of fish protein as affected by vacuum freeze-drying is still limited as so far.

Vacuum spray-drying is a new technique used to turn liquid/slurry food into a powder by dispersing the liquid into a controlled drop size spray and subsequently evaporating at a low temperature $\left(40-80^{\circ} \mathrm{C}\right)$, depending on the degree of vacuum [12]. As compared with some traditional drying methods like spray-drying $\left(120-180^{\circ} \mathrm{C}\right)$, hot air drying, and drum drying, it is the preferred method for drying of many food products containing thermally sensitive components [13]. Additionally, it owns advantages over vacuum freezedrying in the aspects of a lower production cost and continuous process [8]. Vacuum spray-drying has been used to produce dried probiotic foods [14] and juice powder [13]. However, no data exist regarding this vacuum spray-drying technique at a low temperature treatment for fish protein.

Therefore, the objectives of this study were to determine the effects of vacuum freeze-drying and vacuum spraydrying on the biochemical properties and functionalities of fish myofibrillar protein from silver carp, in order to provide fundament supports for the development of new fish protein products.

\section{Materials and Methods}

2.1. Materials. Frozen surimi (AAA grade) made from silver carp (Hypophthalmichthys molitrix) was purchased from Jingli Aquatic Products Co., Ltd. (Honghu, China). Reagents bovine serum albumin, 5,5-dithiobis(2-nitrobenzoic acid) (DTNB), adenosine triphosphate (ATP), 1-anilino-8-napthalene sulfonate (ANS) were purchased from SigmaAldrich Trading Co., Ltd. (Shanghai, China). All other chemicals were of analytical grade and purchased from Sinopharm Chemical reagent Co., Ltd. (Shanghai, China).

2.2. Preparation of Fish Protein Powders by Vacuum FreezeDrying and Vacuum Spray-Drying. Vacuum freeze-drying of surimi (predominately fish myofibrillar proteins) was carried out according to the method of Guo et al. [10] using a pilot scale vacuum freeze-dryer (102241, Martin Christ, Osterode, Germany). After drying, the sample was milled to powder using a pulverizer (RT-08HK, Kaichuang Tonghe Technology Development Co., Beijing, China). The vacuum freeze-dried protein powder was vacuum packaged and stored at room temperature until use.

Vacuum spray-drying of fish myofibrillar proteins from surimi was carried out using a vacuum spray-dryer (SP2000, Shun Yi experimental equipment co. LTD., Shanghai, China). The dispersion of myofibrillar proteins from surimi was carried out according to the methods of Huang et al. [15] with some modifications. In brief, frozen surimi was cut into small pieces using a silent cutter (MultiQuick 3, Braun, Germany) at speed 5 for $1 \mathrm{~min}$. The surimi pieces were added with 4 times volume of $0.45 \mathrm{M} \cdot \mathrm{NaCl}$ solution prior to homogenizing at 4,500 rpm/min for $5 \mathrm{~min}$ (FJ-200, Shanghai
Specimen and Models Factory, Shanghai, China). The homogenate was incubated in ice for $2 \mathrm{~h}$ and then centrifuged at $12,000 \times g$ for $10 \mathrm{~min}$ (J-26XP, Beckman Coulter Inc., Fullerton, CA, USA). The supernatant was added with 10 times volume of cold deionized water to precipitate myofibrillar proteins. The obtained myofibrillar proteins sample with a protein concentration of $10 \mathrm{mg} / \mathrm{ml}$ [16] was subjected to vacuum spray-drying under the following parameters: heating temperature $60^{\circ} \mathrm{C}$, vacuum $0.04 \mathrm{MPa}$, pumping rate $800 \mathrm{ml} / \mathrm{h}$, and firing frequency $1 / \mathrm{s}$. The vacuum spray-dried protein powder was vacuum packaged and stored at room temperature until use.

2.3. Determination of Biochemical Properties. The solubilization of myofibrillar proteins for determining biochemical properties including free sulfhydryl content, surface hydrophobicity, and $\mathrm{Ca}^{2+}$-ATPase activity was carried out according to the method of Yin et al. [17]. Frozen surimi, vacuum freeze-dried protein powder, and vacuum spraydried protein powder was solubilized with $0.6 \mathrm{M} \mathrm{KCl}$ solution containing $20 \mathrm{mM}$ Tris- $\mathrm{HCl}$ (pH 7.0) prior to centrifuging at $18,000 \times g(\mathrm{~J}-26 \mathrm{XP}$, Beckman Coulter Inc., Fullerton, CA, USA) under $4^{\circ} \mathrm{C}$ for $30 \mathrm{~min}$. After the centrifugation, the supernatant was filtered (Number $1 \mathrm{Wa}$ terman paper, Xinhua, Filter Paper Co., Ltd., Hangzhou, China) and used for analyzing the abovementioned biochemical properties. In brief, the determinations of the free sulfhydryl content and $\mathrm{Ca}^{2+}$-ATPase activity were carried out according to the method of Zhang et al. [18] using a spectrophotometer (722 s, Shanghai Precision and Scientific Instrument Co., Ltd., China) with absorbance at 412 and $660 \mathrm{~nm}$, respectively. Surface hydrophobicity was determined under the method of Ma et al. [7] by using a spectrofluorometer (RF-1501, Shimadzu, Kyoto, Japan) with emission and excitation wavelength at $470 \mathrm{~nm}$ and $390 \mathrm{~nm}$, respectively.

2.4. Determination of Solubility. Solubilities of myofibrillar proteins from frozen surimi, vacuum freeze-dried protein powder, and vacuum spray-dried protein powder were determined using the method of Poowakanjana and Park [19]. The soluble proteins and total proteins were extracted using $0.6 \mathrm{M} \cdot \mathrm{KCl}$ and $5 \mathrm{~g} / 100 \mathrm{ml}$ sodium dodecyl sulfonate (SDS) solutions, respectively. The protein concentrations were measured by following the method of Lowry et al. [16]. Solubility was expressed as gram-soluble protein per gram total protein.

2.5. Determination of Emulsifying Properties. The emulsifying activity index (EAI) and emulsion stability index (ESI) were evaluated to determine the emulsifying properties according to the method as described by Chen et al. [20] with some modifications. The extracted myofibrillar proteins (as detailed above in 2.2) were adjusted to $1 \mathrm{mg} / \mathrm{ml}$ [16] prior to mixing with soy oil. The protein-oil mixture was homogenized at 15,000 rpm for 2 min (FJ-200, Shanghai Specimen and Models Factory, Shanghai, China). The emulsion was 
added with SDS solution $(0.1 \mathrm{~g} / 100 \mathrm{ml})$ and then subjected to measuring absorbance at $500 \mathrm{~nm}$ using a spectrophotometer (722 s, Shanghai Precision and Scientific Instrument Co., Ltd., China). The obtained absorbance values at $0 \mathrm{~min}$ and 10 min were used to calculate the EAI and ESI according to the equation described by Chen et al. [20].

2.6. Determination of Water Retention Capacity. Water retention capacity was determined by the method of Gong et al. [21]. In brief, the sample was added with deionized water and then stirred homogeneously. The homogenate was centrifuged at $3,000 \times g$ for $10 \mathrm{~min}$ (TDL-5A, Fulgor Instruments Ltd., Shanghai, China). After the centrifugation, the resulting pellet was collected. Water content of the pellet was determined by heating at $105^{\circ} \mathrm{C}$ until a constant weight was reached. The pellet was resolved in SDS solution $(5 \mathrm{~g} /$ $100 \mathrm{ml}$ ) prior to measuring the total protein content using the method of Lowry et al. [16]. Water retention capacity was expressed as gram water per gram protein in the pellet.

2.7. Analysis of Thermal Stability. Thermal stability of myofibrillar proteins was analyzed according to the method of Yongsawatdigul and Park [22]. Surimi sample and protein powders were scanned at $5.0^{\circ} \mathrm{C} / \mathrm{min}$ over the range of $10-$ $90^{\circ} \mathrm{C}$ using the Q2000 Series differential scanning calorimeter (Netzsch, Selb, Germany). Endothermic transition peak temperature $\left(T_{\mathrm{p}}\right)$ and enthalpy $(\Delta \mathrm{H})$ were estimated from the obtained thermogram using the PeakFit v 4.12 software (SeaSolve Software Inc., Framingham, MA, USA). Before the scanning, the dried protein powders were added with deionized water to obtain the same moisture content as the frozen surimi (76\%).

2.8. Determination of Secondary Structure. Circular dichroism (CD) spectrum was obtained according to the method of Jiang et al. [23] by scanning the myofibrillar proteins (as detailed above in 2.2) within the wavelength range of 190-250 nm using a Jasco J-1500 spectropolarimeter (Jasco Co. Ltd., Tokyo, Japan). The secondary structure ( $\alpha$-helix, $\beta$-sheets, $\beta$-turns, and random coil) were calculated as in Yang et al. [24]. Before the scanning, the myofibrillar proteins sample was adjusted to a protein concentration of $0.05 \mathrm{mg} / \mathrm{ml}$ using deionized water.

2.9. Measurement of Fluorescence Spectrum. Fluorescence spectrum was obtained according to the method of Jiang et al. [23] by scanning the myofibrillar proteins (as detailed above in 2.2) with the excitation wavelength at $280 \mathrm{~nm}$ and the emission wavelength at $200-500 \mathrm{~nm}$ using a spectrofluorometer (RF-1501, Shimadzu, Kyoto, Japan). Before the scanning, the myofibrillar proteins sample was diluted to $1 \mathrm{mg} / \mathrm{ml}$.

2.10. Morphology Observation. The morphologies of vacuum freeze-dried protein powder and vacuum spray-dried protein powder were observed using a scanning electron microscope (JSM-6390 PLV, JEOL, Tokyo, Japan) with an accelerating voltage of $20 \mathrm{KV}$. The samples were sputtercoated with gold before the observation.

2.11. Statistical Analysis. Statistical analysis was conducted using the SAS program (V8, SAS Institute Inc, Carry, NC, USA). Significant differences were tested by analysis of variance, followed by Duncan's multiple-range test at $p<0.05$.

\section{Results and Discussion}

3.1. Biochemical Properties. Biochemical properties including free sulfhydryl content, $\mathrm{Ca}^{2+}$-ATPase activity, and surface hydrophobicity are sensitive indicators widely used to monitor the denaturation of fish proteins [7, 17, 18]. Effects of vacuum freeze-drying and vacuum spray-drying on free sulfhydryl content, $\mathrm{Ca}^{2+}$-ATPase activity, and surface hydrophobicity of myofibrillar proteins from silver carp are shown in Table 1. After vacuum freeze-drying, $\mathrm{Ca}^{2+}$-ATPase activity $(\mu \mathrm{mol} \mathrm{Pi} / \mathrm{mg}$ protein/min) significantly decreased $(p<0.05)$ from 23.5 to 9.0 , while free sulfhydryl content (mol/10 $\mathrm{g}$ protein) and surface hydrophobicity significantly increased $(p<0.05)$ from 5.3 and 51.3 to 8.4 and 226.2, respectively. Results indicated that the fish myofibrillar proteins were partially denatured after vacuum freeze-drying, which were consistent with the report by Guo et al. [10]. As for the native structure of a protein, it is the net results of various repulsive and attractive interactions emanating from assorted intramolecular forces and interaction of various protein groups with surrounding water molecules [25]. The denaturation of fish myofibrillar proteins by vacuum freeze-drying was mainly due to the removing of surrounding water molecules from proteins during freezing and drying steps, which might transfer the hydrogen proton to the carboxyl group, decrease charge density, and enhance hydrophobic interaction of the proteins [26].

After vacuum spray-drying, free sulfhydryl content, $\mathrm{Ca}^{2+}$-ATPase activity, and surface hydrophobicity were determined to be $6.8 \mathrm{~mol} / 10^{6} \mathrm{~g}$ protein, $4.4 \mu \cdot \mathrm{mol} \mathrm{Pi} / \mathrm{g}$ protein/min, and 275.8, respectively (Table 1). As compared with vacuum freeze-drying, the $\mathrm{Ca}^{2+}$-ATPase activity of the myofibrillar proteins under vacuum spraydrying was significantly lower $(p<0.05)$ while surface hydrophobicity was higher $(p<0.05)$, suggesting the myofibrillar proteins were denatured to a higher degree. It was similar to the results reported by Vincenzetti et al. [27] that spray-drying denatured whey proteins from donkey milk more pronouncedly than freeze-drying. The denaturation of proteins by vacuum spray-drying could also be explained by the dehydration effect [28]. In addition, thermal, evaporation, and interface-related stresses might induce the denaturation of the myofibrillar proteins as well [27], which were primarily involved the alterations of noncovalent interactions including hydrogen bonding, electrostatic interactions, and hydrophobic interactions [25]. 
TABLE 1: Biochemical properties and functionalities of fish myofibrillar proteins without drying (a), with vacuum freeze-drying (b), and with vacuum spray-drying (c).

\begin{tabular}{|c|c|c|c|c|c|c|c|}
\hline Sample & $\begin{array}{c}\text { Free sulfhydryl } \\
\text { content }\left(\mathrm{mol} / 10^{6} \mathrm{~g}\right. \\
\text { protein) }\end{array}$ & $\begin{array}{c}\mathrm{Ca}^{2+}-\mathrm{ATPase} \\
\text { activity }(\mu \cdot \mathrm{mol} \mathrm{pi} / \mathrm{g} \\
\text { protein } / \mathrm{min})\end{array}$ & $\begin{array}{c}\text { Surface } \\
\text { hydrophobicity }\end{array}$ & $\begin{array}{l}\text { Solubility (g- } \\
\text { soluble protein/ } \\
\text { g protein) }\end{array}$ & $\begin{array}{c}\text { Water retention } \\
\text { capacity (g water/ } \\
\text { g protein) }\end{array}$ & $\begin{array}{l}\text { Emulsifying } \\
\text { activity index } \\
\left(\mathrm{m}^{2} / \mathrm{g}\right)\end{array}$ & $\begin{array}{l}\text { Emulsifying } \\
\text { stability index } \\
\text { (min) }\end{array}$ \\
\hline $\mathrm{a}$ & $5.3 \pm 0.6^{\mathrm{A}}$ & $23.5 \pm 0.2^{\mathrm{C}}$ & $51.3 \pm 11.6^{\mathrm{A}}$ & $0.62 \pm 0.06^{\mathrm{B}}$ & & $1.36 \pm 0.02^{\mathrm{B}}$ & $66.0 \pm 13.4^{\mathrm{A}}$ \\
\hline $\mathrm{b}$ & & $9.0 \pm 0.5^{\mathrm{B}}$ & $226.2 \pm$ & $0.21 \pm 0.01^{\mathrm{A}}$ & $4.2 \pm 0.7^{\mathrm{A}}$ & $1.27 \pm 0.03^{\mathrm{A}}$ & $167.0 \pm 10.6^{\mathrm{B}}$ \\
\hline c & $6.8 \pm 0.4^{\mathrm{B}}$ & $4.4 \pm 0.7^{\mathrm{A}}$ & $275.8 \pm 38.2^{\mathrm{B}}$ & $0.22 \pm 0.02^{\mathrm{A}}$ & $13.1 \pm 0.4^{\mathrm{C}}$ & $1.45 \pm 0.02^{\mathrm{C}}$ & $478.1 \pm 15.5^{\mathrm{C}}$ \\
\hline
\end{tabular}

Mean \pm SD (standard deviation) from at least two technological replications with three analytical replications each. Different capital letters within the same column indicate a significant difference $(p<0.05)$.

3.2. Solubility. The functional properties of proteins are often affected by protein's solubility, and those most affected are water retention capacity, foaming, emulsifying, etc. Solubility of fish myofibrillar proteins decreased from $0.62 \mathrm{~g} / \mathrm{g}$ to 0.21 and $0.22 \mathrm{~g} / \mathrm{g}$ after vacuum freeze-drying and vacuum spraydrying, respectively. Hydrophobic interaction is one of the major reasons that influence the solubility characteristics of proteins; i.e., hydrophobic interaction promotes proteinprotein interactions and generally results in decreased solubility [25].

3.3. Water Retention Capacity. Hydration and retention capacity of added water are important properties of fish myofibrillar proteins, which influence the performance of those proteins in the food system and the acceptability of fish myofibrillar protein-based products [29]. As shown in Table 1 , water retention capacity of myofibrillar proteins decreased from 6.4 to $4.2 \mathrm{~g}$ water/g protein after vacuum freeze-drying. The decrease of water retention capacity might be attributed to the losses of soluble proteins and lower availability of polar amino acids in vacuum freezedried samples [5]. However, the water retention capacity of myofibrillar proteins significantly increased to $13.1 \mathrm{~g}$ water $/ \mathrm{g}$ protein after vacuum spray-drying. It might be due to an increase in the surface area to mass ratio with exposure of some functional groups previously buried inside [25].

3.4. Emulsifying Properties. Fish myofibrillar proteins possess excellent emulsifying properties, which is attributed to the unique structure (high length-to-diameter ratio) of the predominate component myosin as well as to its bipolar nature (hydrophobic head and hydrophilic tail) [29]. Effects of vacuum freeze-drying and vacuum spray-drying on emulsifying properties including emulsifying activity index and emulsifying stability index of myofibrillar proteins from silver carp are shown in Table 1. Emulsifying activity index of the myofibrillar proteins was slightly $(p<0.05)$ changed after drying. However, the emulsifying stability index was increased $(p<0.05)$ by 2 -folds and 8 -folds after vacuum freeze-drying and vacuum spray-drying, respectively. Researchers have reported that partial denaturation of proteins by various treatments prior to emulsifying improved their emulsifying stability, which was primarily due to increase of molecular flexibility and surface hydrophobicity of the treated proteins $[21,25,30]$. With respect to vacuum freezedrying, myofibrillar proteins under vacuum spray-drying had higher surface hydrophobicity (Table 1) and more flexible structure as denoted by a lower $\alpha$-helical percentage (Figure 1). As a result, vacuum spray-drying showed more pronounced effect on improving the emulsifying stability of the fish myofibrillar proteins.

3.5. Thermal Stability. DSC thermal profiles of fish myofibrillar proteins from silver carp under different drying methods are depicted in Figure 2. Multiple endothermic peaks were observed in the DSC thermal profiles as fish myofibrillar proteins are composited by various types of proteins (predominately myosin and actin) and their subunits (e.g., head and rod of myosin) [31]. The sample without heating exhibited four major transition peaks at 43.9, 49.3, 55.1 , and $71.6^{\circ} \mathrm{C}$, respectively. The first three peaks were likely associated with the transitions of myosin, while the fourth peak was assigned to actin [22].

After vacuum freeze-drying, those peak values slightly shifted to $44.2,49.7,54.9$, and $71.2^{\circ} \mathrm{C}$. In addition, it was well noted that enthalpies of the two fractions (myosin and actin) of fish myofibrillar slightly decreased after vacuum freezedrying. After vacuum spray-drying, the peak near $44.2^{\circ} \mathrm{C}$ disappeared and the transition enthalpies dramatically decreased. During the heating procedure, the native structure of the protein molecule is alternated to a denatured form after the disruption of hydrophobic interactions and breakdown of hydrogen bonds, resulting in the formation of endothermic peaks of the thermogram [22]. Results proved once again that the fish myofibrillar proteins were partially denatured after drying, and the sample under vacuum spraydrying was denatured to a higher degree.

3.6. Secondary Structure. The calculated percentage secondary structure is depicted in Figure 1. The percentage of $\alpha$-helical of fish myofibrillar proteins was determined to be $36.8 \%$, which was in accordance with the results $(35.0 \%$ $\alpha$-helical) of Yin et al. [17]. The percentage of $\alpha$-helical decreased to 30.4 and $18.4 \%$ after vacuum freeze-drying and vacuum spray-drying, respectively. Simultaneously, the percentage of the $\beta$-sheet increased from $11.0 \%$ to $44.3 \%$ and $51.5 \%$, respectively. The secondary structure of protein is determined by electrostatic interactions and hydrogen bonds between amino acids [25, 32]. When proteins in $\alpha$-helical types can be denatured by thermal, freezing, oxidation, ultrasonic treatment, or shearing, $\alpha$-helical usually tends to be alternated into the $\beta$-sheet $[10,17,23]$, of which 


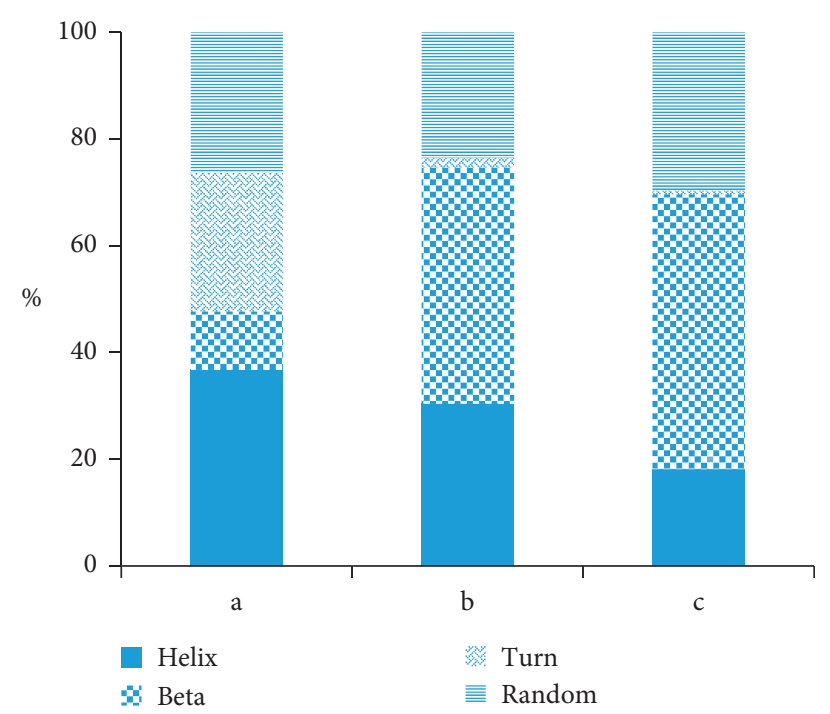

FIGURE 1: The percentage secondary structure of fish myofibrillar proteins without drying (a), with vacuum freeze-drying (b), and with vacuum spray-drying $(\mathrm{c})$.

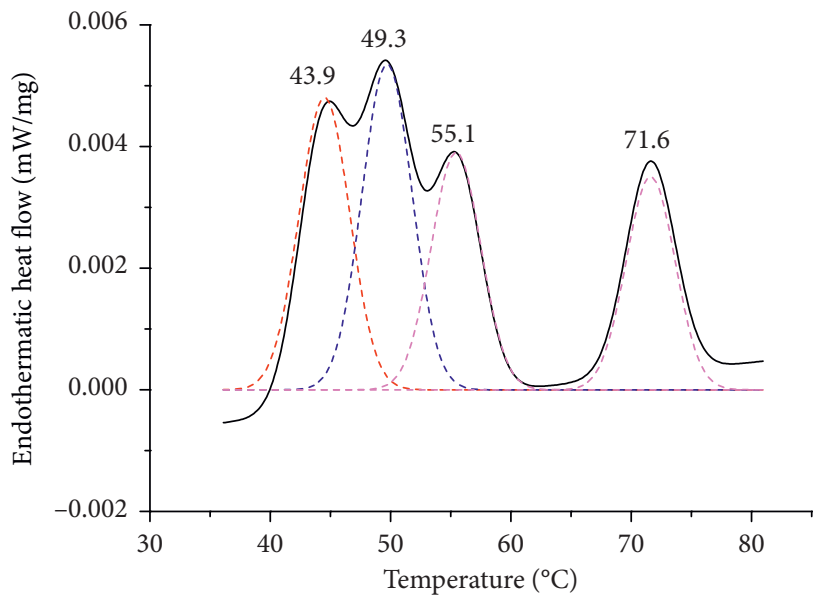

(a)

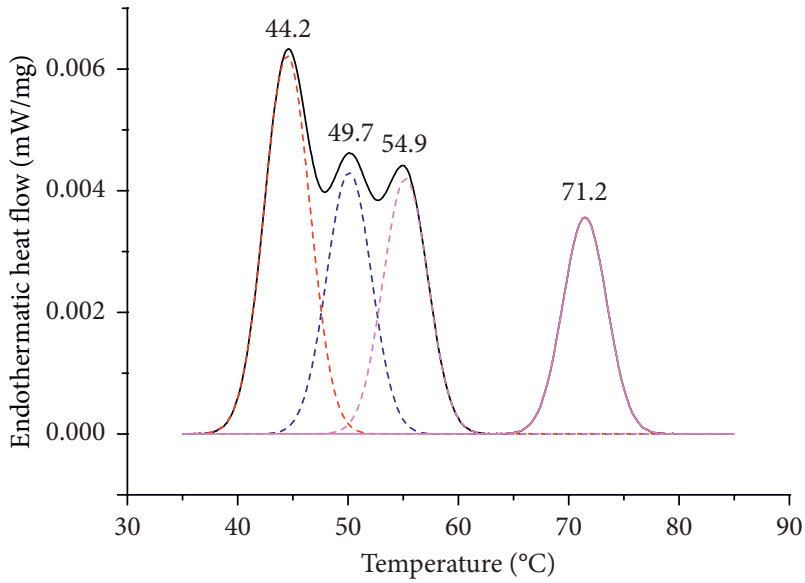

(b)

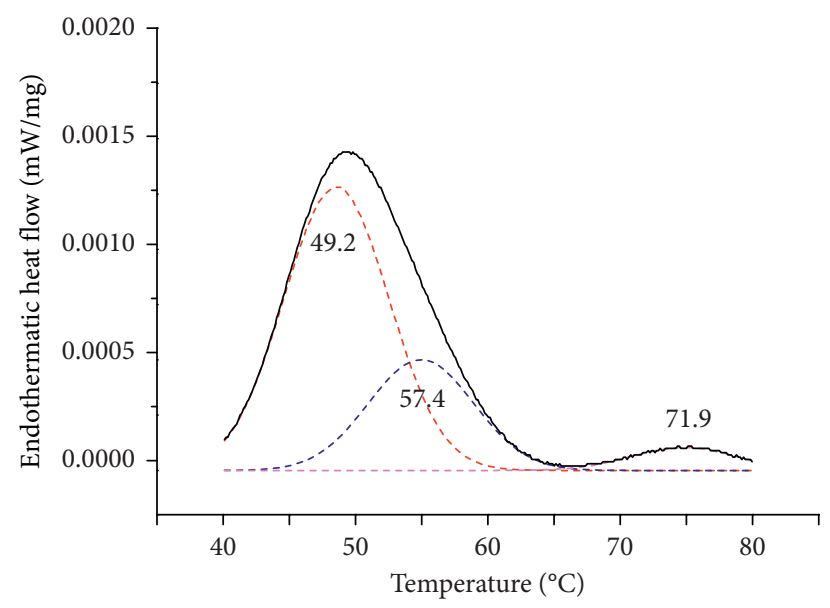

(c)

FIGURE 2: DSC thermographs of fish myofibrillar proteins without drying (a), with vacuum freeze-drying (b), and with vacuum spray-drying (c) (solid lines), together with their computer-fitted differential endotherms (dotted lines). 


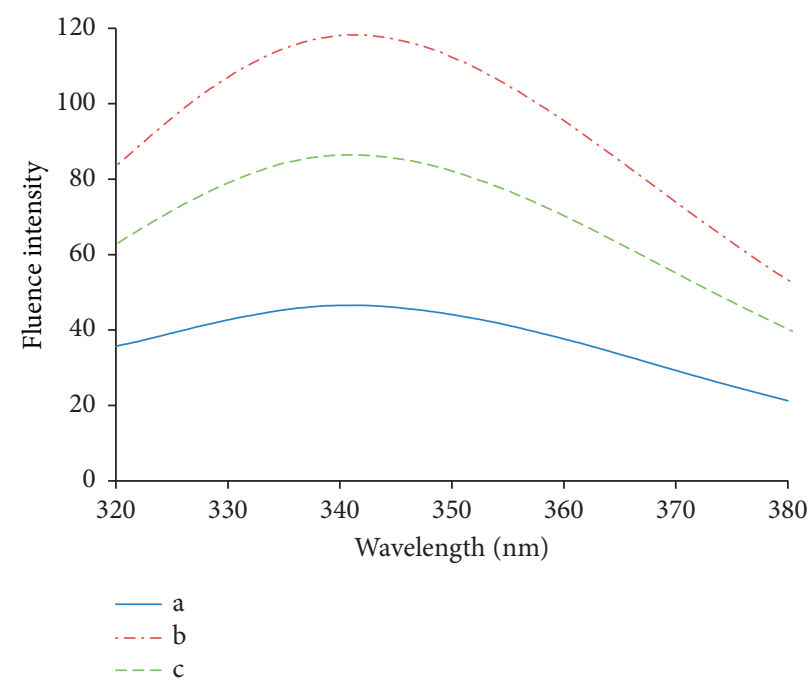

FIGURE 3: Fluorescence spectra of fish myofibrillar proteins without drying (a), with vacuum freeze-drying (b), and with vacuum spraydrying (c).

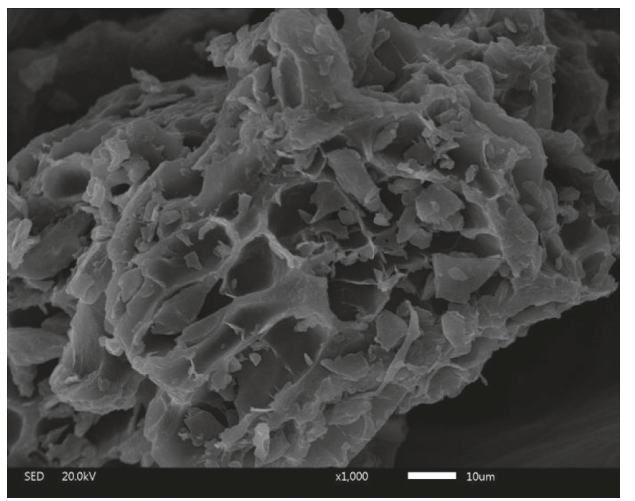

(a)

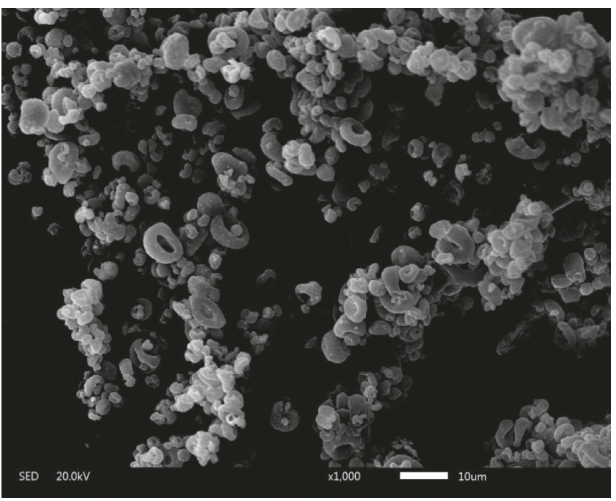

(b)

FIGURE 4: Electron scanning microscopy images of vacuum freeze-dried (a) and vacuum spray-dried (b) fish protein powders.

the structure is generally more thermally stable. Results indicated the fish myofibrillar proteins were unfolded and turned to form a more flexible structure after vacuum freezedrying, which was in agreement with the report by Guo et al. [10]. With respect to vacuum freeze-drying, vacuum spraydrying changed the secondary structure of the fish myofibrillar proteins more pronouncedly.

3.7. Intrinsic Fluorescence Spectra. The intrinsic fluorescence intensity of proteins is particularly sensitive to the polarity of its microenvironments and, hence, is widely applied to monitor tertiary structure changes in the proteins [33]. As shown in Figure 3, peak intensity of fish myofibrillar proteins was located at $340 \mathrm{~nm}$ in the fluorescence spectra, which was in accordance with the report in the literature [23]. The fluorescence intensity was obviously increased after both vacuum freeze-drying and vacuum spray-drying. It was due to the exposure of buried amino acids with intrinsic fluorescence properties, including phenylalanine (Phe), tyrosine (Tyr), and tryptophan (Trp) [23]. This suggested strongly that drying induced transformation of fish myofibrillar proteins into unfolded and more flexible conformation. Surprisingly, as compared with vacuum freeze-drying, the fluorescence intensity of the fish myofibrillar proteins under vacuum spray-drying was obviously lower. It might be related to the oxidation of those exposed amino acids, which resulted in the quenching of fluorescence intensity [23, 33].

3.8. Morphology. The SEM micrographs of fish myofibrillar proteins powder under vacuum freeze-drying and vacuum spray-drying are shown in Figure 4. The micrographs indicate that vacuum freeze-dried powder formed a spongy structure, which was due to the sublimation of small ice crystals embedded in the frozen sample [5]. The powder under vacuum spray-drying mostly appeared spherical in shape and hollow inside. The hollow interior observed in the spray-dried fish protein powder might be due to the formation of glassy skin in the early drying stage. It has been reported that the low moisture diffusivity in the glassy skin 
of proteins led to internal vaporization and periodic escape of water which resulted into the formation of hollow in the dried particles [34]. The morphology may affect the bulk density and hydration properties of the powders.

\section{Conclusion}

Fish myofibrillar proteins powders were produced through vacuum freeze-drying and vacuum spray-drying using industrial surimi as the starting material. The drying method significantly influenced the biochemical properties and functionalities of the dried fish protein powder. With respect to vacuum freeze-drying, fish myofibrillar proteins were denatured/unfolded to a higher degree by vacuum spraydrying which were denoted by the higher surface hydrophobicity while lower $\mathrm{Ca}^{2+}$-ATPase activity and percentage of $\alpha$-helical structure. The spray-dried fish protein powder had better water retention capacity and emulsifying stability, but the same solubility as that of freeze-dried fish protein powder. Thus, vacuum freeze-drying and vacuum spraydrying methods can be used to produce fish protein powders with different structures and different functionalities.

\section{Data Availability}

The data used to support the findings of this study are available from the corresponding author upon request.

\section{Conflicts of Interest}

The authors declare that there are no conflicts of interest.

\section{Authors' Contributions}

Jianzhen Niu and Binfan Zhao contributed equally to this work.

\section{Acknowledgments}

The project was supported by Key Laboratory of Refrigeration and Conditioning Aquatic Products Processing, Ministry of Agriculture and Rural Affairs (KLRCAPP201802) and China Agricultural Research System (CARS-45-27).

\section{References}

[1] FAOSTAT, The State of World Fisheries and Aquaculture, Food and Agriculture Organization of the United Nations, Rome, Italy, 2018, http://www.fao.org.

[2] Y. Zhang, Q. Wang, Y. Bi, K.-W. Cheng, and F. Chen, "Nutritional and functional activities of protein from steamed, baked, and high hydrostatic pressure treated cod (Gadus morhua)," Food Control, vol. 96, pp. 9-15, 2019.

[3] T. Yin, J. W. Park, and S. Xiong, "Effects of micron fish bone with different particle size on the properties of silver carp (Hypophthalmichthys molitrix) surimi gels," Journal of Food Quality, vol. 2017, Article ID 8078062, 8 pages, 2017.

[4] J. W. Park, D. Graves, R. Draves, and J. Yongsawatdigul, "Manufacture of surimi: harvest to frozen block," in Surimi and Surimi Seafood, J. W. Park, Ed., pp. 55-100, CRC Press, Boca Raton, FL, USA, 2014.
[5] D. Dehnad, S. M. Jafari, and M. Afrasiabi, "Influence of drying on functional properties of food biopolymers: from traditional to novel dehydration techniques," Trends in Food Science \& Technology, vol. 57, pp. 116-131, 2016.

[6] J. Ma, J.-H. Qu, and D.-W. Sun, "Developing hyperspectral prediction model for investigating dehydrating and rehydrating mass changes of vacuum freeze dried grass carp fillets," Food and Bioproducts Processing, vol. 104, pp. 66-76, 2017.

[7] Y. Ma, S. Xiong, J. You, Y. Hu, Q. Huang, and T. Yin, "Effects of vacuum chopping on physicochemical and gelation properties of myofibrillar proteins from silver carp (Hypophthalmichthys molitrix)," Food Chemistry, vol. 245, pp. 557-563, 2018.

[8] C. Landymore, T. D. Durance, A. Singh, A. P. Singh, and D. D. Kitts, "Comparing different dehydration methods on protein quality of krill (Euphausia pacifica)," Food Research International, vol. 119, pp. 276-282, 2019.

[9] C. S. Song, J. H. Nam, C.-J. Kim, and S. T. Ro, "A finite volume analysis of vacuum freeze drying processes of skim milk solution in trays and vials," Drying Technology, vol. 20, no. 2, pp. 283-305, 2002.

[10] X. Guo, L. Shi, S. Xiong et al., "Gelling properties of vacuumfreeze dried surimi powder as influenced by heating method and microbial transglutaminase," $L W T$, vol. 99, pp. 105-111, 2019.

[11] J. Reynolds, J. W. Park, and Y. J. Choi, "Physicochemical properties of pacific whiting surimi as affected by various freezing and storage conditions," Journal of Food Science, vol. 67, no. 6, pp. 2072-2078, 2002.

[12] Y. Kitamura and Y. Yanase, "Development of vacuum spray drying system for probiotics powder," in New Topics in Food Engineering, M. A. Comeau, Ed., Nova Science Publishers Inc, New York, NY, USA, 2011.

[13] M. Z. Islam, Y. Kitamura, Y. Yamano, and M. kitamura, "Effect of vacuum spray drying on the physicochemical properties, water sorption and glass transition phenomenon of orange juice powder," Journal of Food Engineering, vol. 169, pp. 131-140, 2016.

[14] D. Semyonov, O. Ramon, and E. Shimoni, "Using ultrasonic vacuum spray dryer to produce highly viable dry probiotics," LWT-Food Science and Technology, vol. 44, no. 9, pp. 18441852, 2011.

[15] J. Huang, A. M. Bakry, S. Zeng et al., "Effect of phosphates on gelling characteristics and water mobility of myofibrillar protein from grass carp (Ctenopharyngodon idellus)," Food Chemistry, vol. 272, pp. 84-92, 2019.

[16] O. H. Lowry, A. I. Rosebrough, A. L. Farr, and R. J. Randall, "Protein measurement with the folin phenol reagent," Journal of Biological Chemistry, vol. 193, pp. 265-275, 1951.

[17] T. Yin, Y. He, L. Liu et al., "Structural and biochemical properties of silver carp surimi as affected by comminution method," Food Chemistry, vol. 287, pp. 85-92, 2019.

[18] R. Zhang, S. Xiong, J. You, Y. Hu, R. Liu, and T. Yin, "Effects of ozone treatments on the physicochemical changes of myofibrillar proteins from silver carp (Hypophthalmichthys molitrix) during frozen storage," Journal of Food Quality, vol. 2017, Article ID 9506596, 9 pages, 2017.

[19] S. Poowakanjana and J. W. Park, "Biochemical characterisation of Alaska pollock, pacific whiting, and threadfin bream surimi as affected by comminution conditions," Food Chemistry, vol. 138, no. 1, pp. 200-207, 2013.

[20] X. Chen, R. Zhou, X. Xu, G. Zhou, and D. Liu, "Structural modification by high-pressure homogenization for improved 
functional properties of freeze-dried myofibrillar proteins powder," Food Research International, vol. 100, pp. 193-200, 2017.

[21] K.-J. Gong, A.-M. Shi, H.-Z. Liu et al., "Emulsifying properties and structure changes of spray and freeze-dried peanut protein isolate," Journal of Food Engineering, vol. 170, pp. 33-40, 2016.

[22] J. Yongsawatdigul and J. W. Park, "Thermal denaturation and aggregation of threadfin bream actomyosin," Food Chemistry, vol. 83, no. 3, pp. 409-416, 2003.

[23] W. Jiang, Y. He, S. Xiong et al., "Effect of mild ozone oxidation on structural changes of silver carp (Hypophthalmichthys molitrix) myosin," Food and Bioprocess Technology, vol. 10, no. 2, pp. 370-378, 2016.

[24] J. T. Yang, C.-S. C. Wu, and H. M. Martinez, "[11] Calculation of protein conformation from circular dichroism," Methods in Enzymology, vol. 130, pp. 208-269, 1986.

[25] S. Damodaran, "Amino acids, peptides, and proteins," in Food Chemistry, S. Damodaran, K. L. Parkin, and O. W. Fennema, Eds., CRC Press, Boca Raton, FL, USA, 2009.

[26] J. W. Park and T. C. Lanier, "Combined effects of phosphates and sugar or polyol on protein stabilization of fish myofibrilsffects of phosphates and sugar or polyol on protein stabilization of fish myofibrils," Journal of Food Science, vol. 52, no. 6, pp. 1509-1513, 1987.

[27] S. Vincenzetti, T. Cecchi, D. R. Perinelli et al., "Effects of freeze-drying and spray-drying on donkey milk volatile compounds and whey proteins stability," LWT, vol. 88, pp. 189-195, 2018.

[28] M. A. Haque, J. Chen, P. Aldred, and B. Adhikari, "Drying and denaturation characteristics of whey protein isolate in the presence of lactose and trehalose," Food Chemistry, vol. 177, pp. 8-16, 2015.

[29] G. Strasburg, Y. L. Xiong, and W. Chiang, "Physiology and chemistry of ediable muscle tissues," in Food Chemistry, S. Damodaran, K. L. Parkin, and O. W. Fennema, Eds., pp. 923-974, CRC Press, Boca Raton, FL, USA, 2009.

[30] D. Wu, C. Wu, W. Ma, Z. Wang, C. Yu, and M. Du, "Effects of ultrasound treatment on the physicochemical and emulsifying properties of proteins from scallops (Chlamys farreri)," Food Hydrocolloids, vol. 89, pp. 707-714, 2019.

[31] T. C. Lanier, J. Yongsawatdigul, and P. Carvajal-Rondanelli, "Surimi and fish proteins: surimi gelation chemistry," in Surimi and Surimi Seafood, J. W. Park, Ed., pp. 101-139, CRC Press, Taylor \& Francis Group LLC., Boca Raton, FL, USA, 2014.

[32] J. Yongsawatdigul and S. Sinsuwan, "Aggregation and conformational changes of tilapia actomyosin as affected by calcium ion during setting," Food Hydrocolloids, vol. 21, no. 3, pp. 359-367, 2007.

[33] Y. Cao, A. D. True, J. Chen, and Y. L. Xiong, "Dual role (antiand pro-oxidant) of gallic acid in mediating myofibrillar protein gelation and gel in vitro digestion," Journal of Agricultural and Food Chemistry, vol. 64, no. 15, pp. 3054-3061, 2016.

[34] B. Wang, Y. P. Timilsena, E. Blanch, and B. Adhikari, "Characteristics of bovine lactoferrin powders produced through spray and freeze drying processes," International Journal of Biological Macromolecules, vol. 95, pp. 985-994, 2017. 


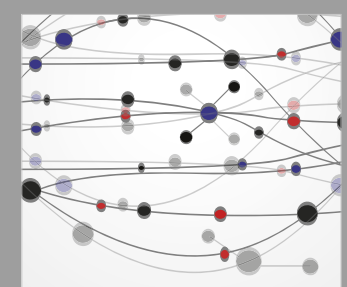

The Scientific World Journal
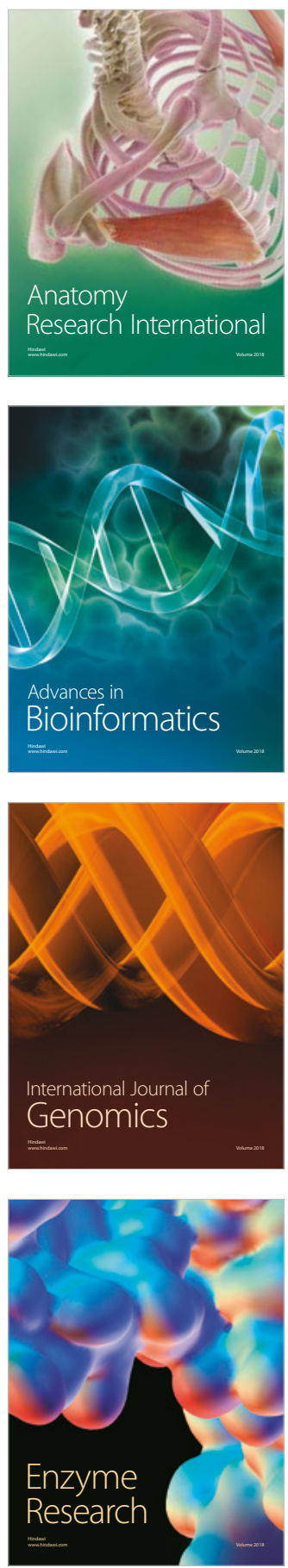
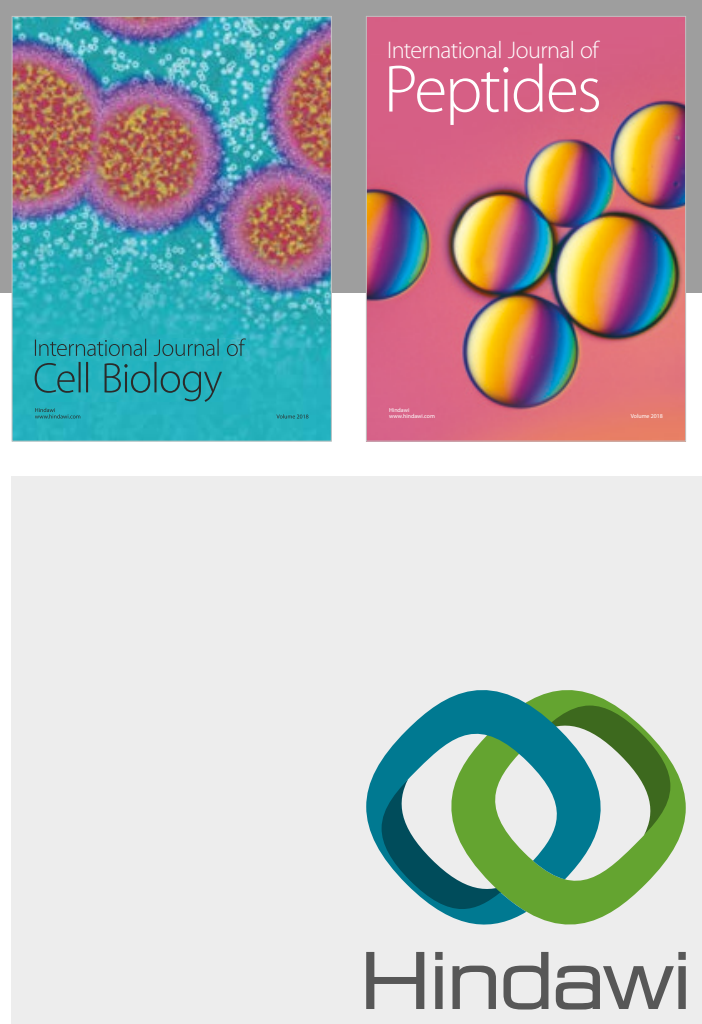

Submit your manuscripts at

www.hindawi.com
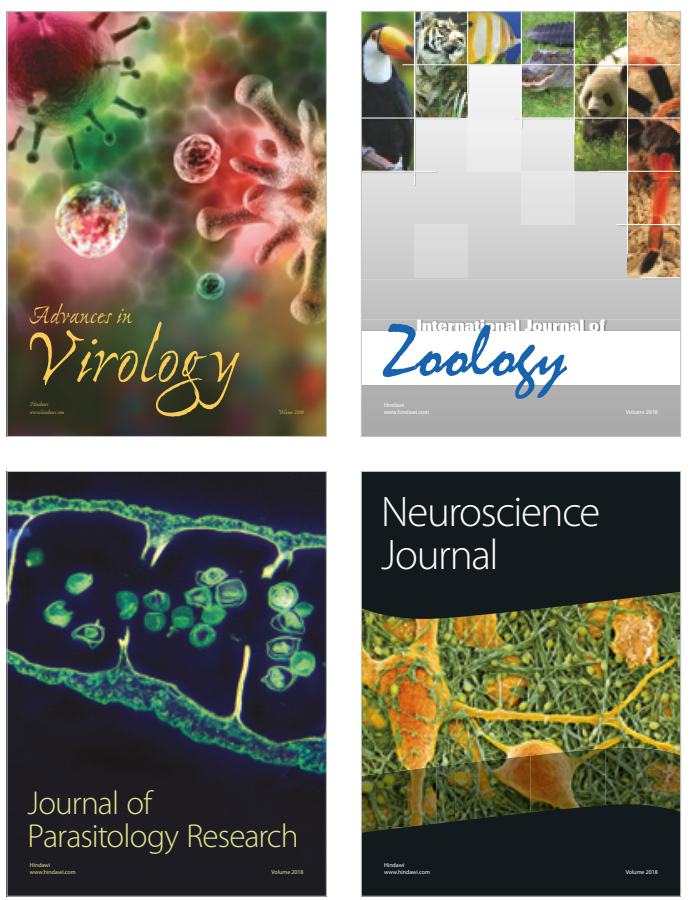
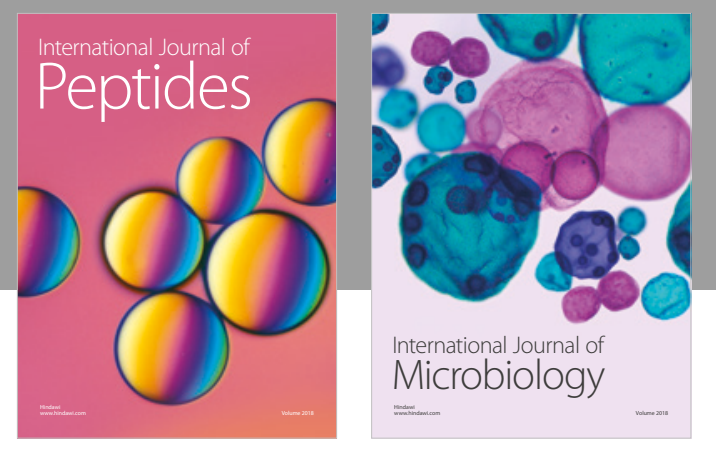

nternational Journal of Microbiology
Journal of
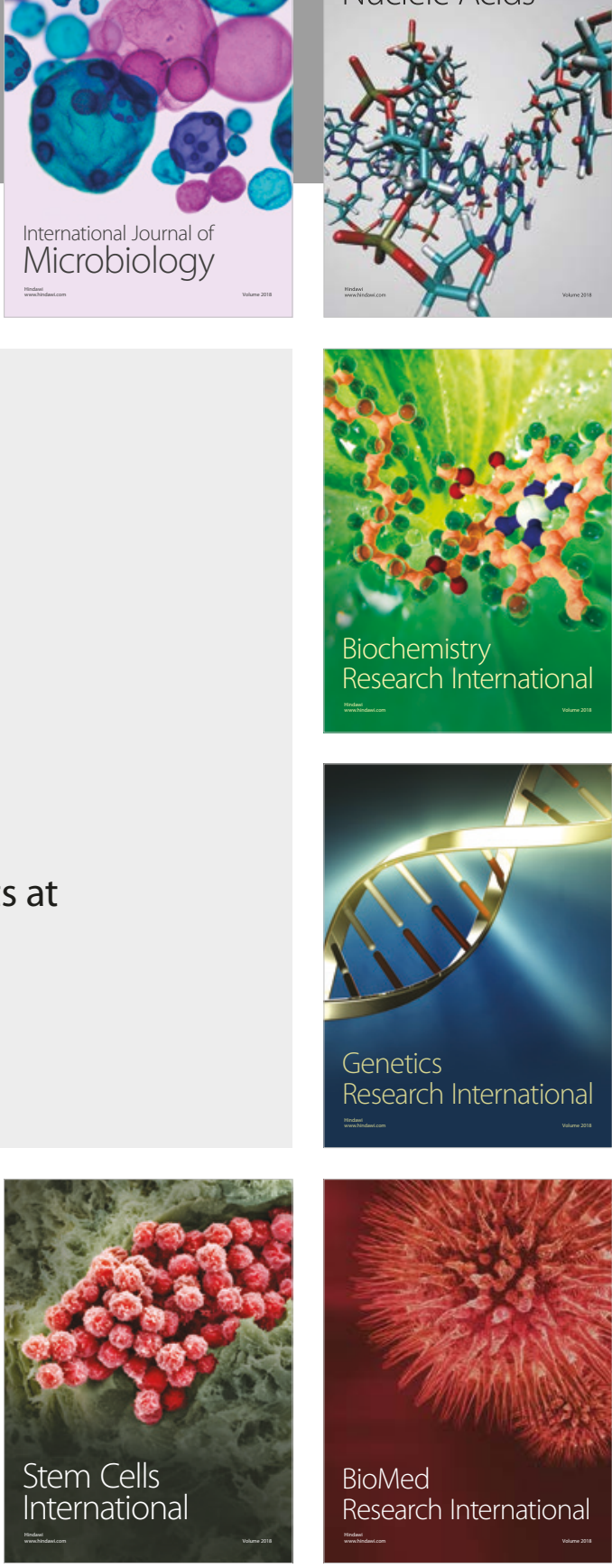
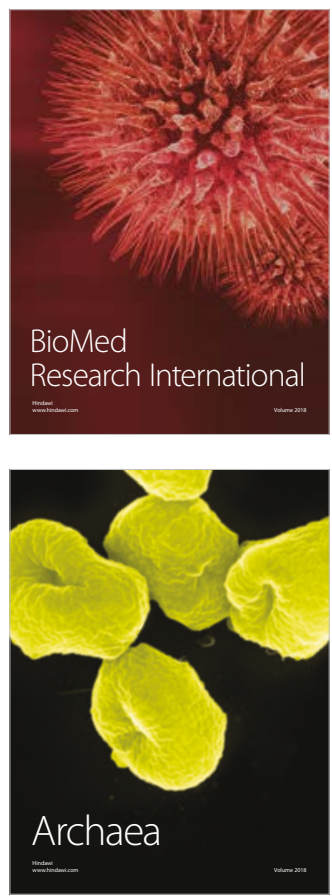